\title{
A New and Simplified Technique of Treating Acute Neuritis in Leprosy, Using Ethyl Chloride Spray
}

DR. DOUGLAS E. HENRY, B.SC., M.B.B.S.,

The Mission to Lepers, Chandkhuri Leprosy Hospital and Homes,

P.O. Baitalpur, via Bhatapara, M.P. India

I N T R O DUCTION

Swollen and painful nerves are fairly frequently found as an annoying complication in the course of leprosy. The nerves most commonly affected are the subcutancous nerves like the ulnars, the lateralpopliteals and the posterior auriculars in their order of frequency. 'They not only give excruciating pain and discomfort to the patient but are also responsible for taking these poor people out of work and later are responsible for the development of deformities like clawhands and dropfect. This is due to the destruction of the nerve fibres which causes the paralysis of the respective muscles.

\section{PA T HOLOG Y}

It has been shown by KHANOLKAR that the nerve tissues are very susceptible to leprosy bacilli which can be found in large numbers even in the nerves of those patients who do not show the bacteria in the skin smears.

The blood and lymph supply of the nerve bundles occurs between the epincurium and the perineurium.

In the course of leprosy these venules and lymphatics are first blocked by the bacteria and because the pressure is more in the arterioles more blood comes in and stagnates. Gradually the pressure here increases to such an extent that there is resultant partial ischaemia of the nerve bundles.

D. BROWN has shown that this partial ischaemia causes a reversible paralysis or loss of conductivity without Wallerian degeneration. If blood again returns to the tissues conductivity also returns. But if the ischaemia is of long duration or if it is absolute then the nerve becomes destroyed and fibrosis take place. The paralysis then is irreversible.

During these episodes the nerves are swollen and tender.

\section{COMMON FORMS OF TREATMENT EMPLOYED}

(I) In early and less severe cases general treatment for reactions usually gives relief.

(2) Injection of novocain or lignocain with or without cortisone around the nerve sometimes gives relief.

(3) Recently novocain or lignocain with cortisone and hyalase have been injected intraneurally and have been found quite effective.

(4) Heat has been used in the form of hot compresses, diathermy or wax baths with varying amount of success. 
(5) Surgery: Nerve stripping or nerve decompression are also used with varying amount of success.

OUR SIMPLIFIED TECHNIQUE

With the increase in the use of cold instead of heat in the modern therapy, we thought of using a cooling agent for the treatment of acutely swollen and tender superficial nerves.

We found that the simplest thing we could lay hold on was ethyl chloride spray. This is cheap, safe and simple. The pain is almost immediately relieved and the patients are quite thankful and return soon to their regular work.

Ethyl chloride is sprayed from a fine nozzle on the tender nerve from a distance of about 20 to $30 \mathrm{~cm}$. so that about 5 to $10 \mathrm{~cm}$. of the skin just over the nerve is thus treated till a fairly good coat of fine ice is formed and remains for about I to 2 minutes.

This procedure, if required, is repeated on the $3^{\text {rd }}$ and $5^{\text {th }}$ day and usually i to 3 applications are quite enough. No bandage is applied and the patient is asked to report as soon as he or she notices more swelling and pain, and this procedure could be safely repeated. If there is accompanying reaction then it is treated on usual lines and apart from some Asprin tablets for a day or two nothing clse is given as medication.

RESULTS OF OUR TRIALS

So far we have treated 25 patients by this method and have found Ethyl chloride spray very useful in 23 cases. There were two failures but one was due to long standing neuritis and had plenty of fibrosis and one was a case having nerve abscess; for these surgery had to be applied.

COMMENTS

Twenty-five is a very small number and we are going ahead with this experiment. I fecl that a properly organised drug trial will be of immense value.

Since Ethyl chloride is cheap and effective and can be used even in simple and primitive field conditions, it has a very good future in the treatment of acute neuritis.

It is also of much use in acute fibrofasciitis like wryneck and pulled dorsal muscle.

Though I have not worked out fully the pathology involved after the use of Ethyl chloride spray yet I feel that in some way the vicious cycle of increase in the pressure in the space between the epineurium and the perineurium is broken and ischaemia to the nerve bundles is relieved, which is responsible for the reduction in swelling and tenderness of the nerves. I feel this requires complete study in a big centre with all laboratory facilities. 


\section{SUMMAR Y}

(i) Acute neuritis in leprosy is discussed including its pathology and treatment.

(ii) A new technique of treating acute neuritis in leprosy by the use of ethyl chloride spray on the skin over these nerves is described. It is assumed that cooling agents may be of more benefit to mankind than hitherto thought.

\section{References}

MUIR, E. Leprosy Diagnosis, Treatment and Prevention, 1948.

cochrane, r. G. Leprosy in 'Theory and Practice, 1960.

Dharmenisa, Notes on L.eprosy, 1960.

Browne, s. G. and hogerzeil, L. M. L.eprosy Review, 32, Oct. 1961.

thangaraj and tuangaraJ, Leprosy Review, 32, Jan. 1961 . 